\title{
Infantile spasms-psychomotor retardation-progressive brain atrophy- basal ganglia disease syndrome
}

INSERM

\section{Source}

INSERM. (1999). Orphanet: an online rare disease and orphan drug data base. Infantile spasms-psychomotor retardation-progressive brain atrophy-basal ganglia disease syndrome. ORPHA:263410

Infantile spasms-psychomotor retardation-prog ressive brain atrophy-basal gang lia disease syndrome is a rare, genetic disorder of thiamine metabolism and transport characterized by infantile spasms progressing to symptomatic generalized or partial seizures, severe global developmental delay, progressive brain atrophy, and bilateral thalamic and basal ganglia lesions. 